\section{Does restrictive right ventricular physiology in the early postoperative period predict subsequent right ventricular restriction after repair of tetralogy of Fallot?}

G Norgård, M A Gatzoulis, M Josen, S Cullen, A N Redington

\begin{abstract}
Objective-To assess the relation between immediate postoperative right ventricular (RV) diastolic physiology and subsequent diastolic function in patients after repair of tetralogy of Fallot.

Design-Serial prospective echocardiographic study early after surgical repair of tetralogy of Fallot and at mid-term follow up.

Setting-Tertiary referral centre.

Patients-34 patients who had repair of tetralogy of Fallot between 1992 and 1995 were studied.
\end{abstract}

Main outcome measures-Restrictive RV physiology defined as antegrade flow in the pulmonary artery in late diastole throughout the respiratory cycle.

Results-Sixteen of the 34 patients had early restrictive RV physiology. The need for transannular patch repair was an independent variable predictive of early restriction (odds ratio 4.3 (1.1-47), $p<0.05)$. Nine of 16 patients with early restriction also had restriction at follow up, while 15 of 16 patients without restrictive RV physiology continued without restriction. Early restriction was the only independent variable predictive of late restriction (odds ratio 6.0 (1.9-273), $\mathrm{p}=\mathbf{0 . 0 1}$ ).

Conclusions-Early and mid-term restrictive RV physiology after repair of tetralogy of Fallot is related to the repair type. Although evidence for this physiology tends to resolve in the first few days after operation, it is highly predictive of subsequent abnormalities of RV diastolic function. Similarly, normal RV diastolic physiology without restriction in the immediate postoperative period persists in the mid-term and may be associated with the long term problems of progressive RV dilatation.

(Heart 1998;79:481-484)

Keywords: restrictive right ventricular physiology; evolution; tetralogy of Fallot; congenital heart disease

$S$ Cullen

A N Redington

Correspondence to: Professor A N Redington, Department of Paediatrics, Royal Brompton Hospital, Sydney Street, London SW3 6NP.

Accepted for publication 2 February 1998

Restrictive right ventricular (RV) physiology as indicated by Doppler detectable antegrade forward flow in the pulmonary artery (PA) in late diastole seems to be an important phenomenon after repair of tetralogy of Fallot. ${ }^{1}$ Although relations with postoperative care, exercise tolerance, QRS prolongation, late arrhythmias, and outflow tract repair have been reported, several unsolved issues relating to this condition remain. ${ }^{2-5}$ While restrictive RV physiology can occur both early and late after repair, ${ }^{23}$ it is not known whether this is the same phenomenon, nor whether the same anatomical substrate is involved. We recently reported that restrictive RV physiology was common at mid-term follow up in patients after repair of tetralogy of Fallot. ${ }^{5}$ In another study by our group, ${ }^{2}$ however, the marker for early restrictive RV physiology (within 24 hours) resolved in most patients before hospital discharge. It is not known whether this finding reflects methodology issues, haemodynamic change immediately after repair, or other contributing factors.

In this study, a cohort of patients examined in the immediate postoperative period were restudied to characterise the relation between early and mid-term RV diastolic physiology and to evaluate further determinants for this condition.

\section{Patients and methods}

Forty five patients who underwent repair of tetralogy of Fallot at the Royal Brompton Hospital, London between 1992 and 1995 had a prospective Doppler examination within 24 hours of repair to evaluate restrictive RV physiology (table 1). Five patients were from abroad, so no attempt was made to include them in the follow up study. All patients were asymptomatic and not receiving regular medication. Fourteen patients were previously reported as part of an early study, ${ }^{2}$ and 24 were reported as part of a mid-term follow up study. ${ }^{5}$ Study protocols were approved by the hospital ethics committee, and informed consent was obtained from 34 of the remaining 40 patients or their parents.

Background clinical information was obtained from medical notes including cardiac catheter reports and surgical discharge summaries. The surgical technique for tetralogy repair in our institution has been reported. ${ }^{5}$

\section{ECHOCARDIOGRAPHY}

Transthoracic echocardiography was perinterfaced with a Hewlett-Packard Sonos 1500 ultrasound system. Spectral Doppler recordings were obtained from the PA, tricuspid valve (TV), and mitral valve (MV). Standard pulsed Doppler at the level of the tips of the valve 
Table 1 Characteristics of patients studied early after tetralogy of Fallot repair

\begin{tabular}{llll}
\hline Variables & $\begin{array}{l}\text { Early restriction } \\
(n=16)\end{array}$ & $\begin{array}{l}\text { Early non-restriction } \\
(n=18)\end{array}$ & $p$ value \\
\hline $\begin{array}{l}\text { Age at operation (years) } \\
\text { Follow up (years) }\end{array}$ & $1.4(0.5-41.1)$ & $0.9(0.5-2.5)$ & 0.1 \\
$\begin{array}{l}\text { Surgical procedure } \\
\text { Blalock-Taussig shunt }\end{array}$ & $1.8(0.6-3.3)$ & $1.7(0.5-3.3)$ & $\mathrm{NS}$ \\
Transannular patch repair & $14^{\star}$ & & \\
Outflow patch & $2^{\star}$ & 6 & \\
Echocardiographic study & & $8^{\star}$ & \\
PA (m/s) & $1.1(0.22)$ & & \\
PR duration (ms) & $171(76)$ & $1.5(0.6)$ & $\mathrm{NS}$ \\
PR duration/vRR & $7.7(3.4)$ & $8.9(1.9)$ & $\mathrm{NS}$ \\
Heart rate (beats/min) & $128(8.5)$ & $150.5(18.0)$ & 0.08 \\
QRS & $71.9(17.3)$ & $70.6(12.2)$ & $\mathrm{N}$ \\
\hline
\end{tabular}

Values are median (range) or mean (SD).

${ }^{\star} \mathrm{p}=0.01, \chi^{2}$ test.

$\mathrm{PA}$, pulmonary artery; PR, pulmonary regurgitation.

Table 2 Determinants for early restrictive right ventricular physiology in patients with repaired tetralogy of Fallot $(n=32)$ assessed by multiple logistic regression analysis

\begin{tabular}{lll}
\hline Independent variables & Odds ratio $(C I)$ & p values \\
\hline Transannular patch repair & $4.3(1.1$ to 47$)$ & $<0.05$ \\
Blalock-Taussig shunt & $0.0(0.2$ to 5.8$)$ & 0.98 \\
Age at operation & $0.27(0.1$ to 4.2$)$ & 0.60 \\
\hline
\end{tabular}

leaflets were recorded from the TV and MV. Pulsed wave Doppler of PA flow with the sample volume midway between the pulmonary valve and PA bifurcation was recorded as reported. $^{23}$ Restrictive RV physiology was present if antegrade PA flow (a wave) in late diastole could be detected throughout the respiratory cycle. ${ }^{1}$ Velocity of the PA a wave and antegrade systolic flow as well as duration of the pulmonary regurgitation signal were measured from the same Doppler tracing. No attempt was made to quantify the volume of pulmonary regurgitation. Continuous wave Doppler was used to assess residual RV outflow tract obstruction, defined as a gradient of more than $40 \mathrm{~mm} \mathrm{Hg}$, and patients with these values were excluded from the final analysis. Recordings were made with simultaneous electrocardiogram, phonocardiogram, and a respiratory tracing. The mean of three measurements were analysed. Early recordings were obtained within 24 hours of surgical repair. TV Doppler was analysed at peak inspiration and MV Doppler at end expiration.

STATISTICAL ANALYSIS

Data are mean (SD) or median with range. Comparisons between groups were performed by the Mann-Whitney U test; $\chi^{2}$ test or Fisher's

Table 3 Characteristics of patients at follow up after tetralogy of Fallot repair

\begin{tabular}{llll}
\hline Variables & $\begin{array}{l}\text { Restriction } \\
(n=10)\end{array}$ & $\begin{array}{l}\text { Non-restriction } \\
(n=22)\end{array}$ & p value \\
\hline $\begin{array}{l}\text { Age at operation (years) } \\
\text { Follow up (years) }\end{array}$ & $1.1(0.5-41.1)$ & $1.1(0.5-9.9)$ & $\mathrm{NS}$ \\
Echocardiography & $2.0(1.0)$ & $1.7(1.1)$ & $\mathrm{NS}$ \\
PA (m/s) & $1.6(0.32)$ & $1.6(0.5)$ & $\mathrm{NS}$ \\
PR duration (ms) & $219.8(52.0)$ & $254.6(40.6)$ & $\mathrm{NS}$ \\
PR duration/VRR & $8.6(2.0)$ & $10.6(1.7)$ & 0.07 \\
TVE deceleration (ms) & $110.9(39.0)$ & $119.6(25.6)$ & 0.2 \\
TVE deceleration/VRR & $4.2(1.6)$ & $4.9(1.7)$ & $<0.05$ \\
E velocity (m/s) & $0.7(0.16)$ & $0.8(0.2)$ & $\mathrm{NS}$ \\
A velocity (m/s) & $0.5(0.2)$ & $0.6(0.16)$ & $\mathrm{NS}$ \\
Heart rate & $91(14.6)$ & $102(16.9)$ & 0.1 \\
QRS & $116.2(15.2)$ & $117.4(12.9)$ & $\mathrm{NS}$
\end{tabular}

$\mathrm{TV}$, tricuspid valve; PA, pulmonary artery; $\mathrm{PR}$, pulmonary regurgitation. exact test was used to assess group differences for categorical variables. Multiple logistic regression with early and late restrictive RV physiology as dependent variables was performed to assess determinants for early and late restriction. Confidence intervals for odds ratios were calculated as $\mathrm{e}^{\mathrm{B} \pm 1.96} \mathrm{SE}$. The null hypothesis was rejected when $\mathrm{p}<0.05$.

\section{Results}

EARLY POSTOPERATIVE DIASTOLIC PHYSIOLOGY Sixteen patients had restrictive RV physiology early after repair. Two of 18 patients without restriction were excluded from the mid-term study: one because of residual pulmonary stenosis, and one because of the presence of a residual ventricular septal defect. Table 1 lists patient characteristics early after repair. $\mathrm{Pa}-$ tients with early restriction tended to be older at repair $(p=0.1)$. Transannular patch repair was present in $87.5 \%$ of patients with restriction and $47 \%$ of those without restriction, respectively $(\mathrm{p}=0.01)$. Table 2 lists determinants for early restriction. The need for transannular patch repair was the only independent predictor for early RV restriction with an odds ratio of $4.3(\mathrm{p}<0.05)$.

\section{MID-TERM DIASTOLIC PHYSIOLOGY}

Table 3 lists patient characteristics at mid-term follow up. Age at repair did not differ between patients with and without restriction. TV $\mathrm{E}$ deceleration time corrected by $\sqrt{\mathrm{RR}}$ was 4.2 (1.6) patients with restriction and 4.9 (1.7) in those without restriction $(p<0.05)$. Table 4 lists determinants for mid-term restriction. Early RV restrictive physiology was the only independent variable associated with mid-term restriction with an odds ratio of $6.0(p=0.01)$.

\section{EVOLUTION OF DIASTOLIC RV PHYSIOLOGY}

Nine of 16 patients with early restriction also had restriction at mid-term follow up, whereas 15 of 16 without restriction continued without restriction. We restudied three of four patients from the study by Cullen et al who had restriction physiology at hospital discharge. ${ }^{2}$ Of these patients, two had restriction at mid-term follow up, and one did not have restriction. Table 5 shows a comparison of variables in patients with early restrictive RV physiology at midterm follow up. TV E deceleration time was significantly shorter in patients in whom restrictive physiology remained rather than in those without late restriction (101.3 v $134.6 \mathrm{~ms}, \mathrm{p}<0.03)$. There was also a tendency for a shorter RR duration and larger antegrade a waves in patients with restriction.

Table 4 Determinants for mid-term restrictive right ventricular physiology after repair of tetralogy of Fallot $(n=32)$

\begin{tabular}{lll}
\hline Variable & Odds ratio $(C I)$ & p value \\
\hline Early restriction & $6.0(1.9$ to 273$)$ & 0.01 \\
Blalock-Taussig shunt & $1.9(0.02$ to 2.0$)$ & 0.17 \\
Cyanotic spells & $0.02(0.1$ to 5.9$)$ & 0.87 \\
Follow up & $0.13(0.3$ to 2.2$)$ & 0.72 \\
\hline
\end{tabular}


Table 5 Characteristics of patients with early and late restriction (group 1) compared to patients with early restriction and late non-restriction (group 2)

\begin{tabular}{llll}
\hline Variables & Group 1 $(n=9)$ & Group 2 $(n=7)$ & p value \\
\hline Age at operation (years) & $1.3(0.5-41.1)$ & $1.5(0.7-9.9)$ & $\mathrm{NS}$ \\
Follow up (years) & $1.9(1.0)$ & $2.0(1.3)$ & $\mathrm{NS}$ \\
Echocardiographic study & & & \\
Heart rate early (beats/min) & $128.0(23.8)$ & $126.6(5.5)$ & $\mathrm{NS}$ \\
Heart rate late (beats/min) & $92.1(15.3)$ & $96.1(11.8)$ & $\mathrm{NS}$ \\
PA (m/s) & $1.7(0.3)$ & $1.5(0.5)$ & $\mathrm{NS}$ \\
PR duration (ms) & $219.6(64.0)$ & $264.8(47.7)$ & $\mathrm{NS}$ \\
PR duration//RR & $8.2(3.8)$ & $10.9(5.3)$ & 0.2 \\
a wave PA (m/s) & $0.37(0.1)$ & $0.28(0.05)$ & 0.15 \\
TVE deceleration (ms) & $101.3(26.3)$ & $134.6(26.4)$ & $<0.03$ \\
TVE deceleration/vRR & $3.8(1.1)$ & $5.4(1.1)$ & $<0.01$ \\
E velocity (m/s) & $0.7(0.16)$ & $0.7(0.2)$ & $\mathrm{NS}$ \\
\hline
\end{tabular}

All parameters, except heart rate early, are follow up data.

a wave, velocity of diastolic forward flow in pulmonary artery (PA); PR, pulmonary regurgitation.

\section{Discussion}

EARLY DIASTOLIC RV PHYSIOLOGY

The finding of restrictive RV physiology in 16 $(47 \%)$ patients early after repair of tetralogy of Fallot is in agreement with the study of Cullen et $a .^{2}$ In this study early restriction is more likely to be present if a transannular patch repair is required. The results are also in accord with our mid-term analysis of the relation between types of repair and diastolic RV function, which also showed that transannular patch repair was an important determinant for mid-term restrictive RV physiology. ${ }^{5}$ It is impossible to predict, however, whether this reflects the effects of such surgery or an intrinsic myocardial problem associated with the need for a transannular patch-that is, whether there is a preoperative anatomical substrate related to subsequent abnormalities of diastolic function.

\section{MID-TERM DIASTOLIC PHYSIOLOGY}

Our finding of resolution of the restrictive pattern in some patients has been previously reported. ${ }^{2}$ In that study, however, the pattern of restrictive RV physiology resolved before hospital discharge in most patients and no later follow up data were available. In our present study, however, many patients with early restriction were also restrictive at a follow up of 1.8 years. Similarly, all but one patient without early non-restriction remained without restriction. Interestingly, the patient who developed restrictive RV physiology at follow up, although not fulfilling inclusion criteria of restriction at that time, had a prominent retrograde a wave in the superior vena cava Doppler recording early after operation. This flow pattern was present in most patients with restriction, and may indicate that this patient had restrictive $\mathrm{RV}$ physiology, perhaps masked by the presence of raised PA diastolic pressure. ${ }^{5}$

EVOLUTION OF RV DIASTOLIC PHYSIOLOGY

Resolution of RV restriction within two weeks of surgical repair and subsequent return in many seems to be paradoxical. This comes back to the earlier question of whether the anatomical or physiological substrate for restrictive physiology is present before operation, whether it is exposed by additional effects of the procedure, only to return later as the RV fails to adapt to volume load imposed by pulmonary regurgitation and somatic growth. Regardless of the mechanism, when mid-term restrictive RV physiology was analysed by multiple logistic regression, early restriction was the only associated independent variable. Interestingly, the length of follow up did not correlate with restriction at mid-term follow up. It seems therefore that the anatomical substrate requiring a transannular patch repair is the most important determinant for early restriction, and mid-term restriction is most likely to occur if early restriction is present.

In our study TV $\mathrm{E}$ wave deceleration time was shorter ${ }^{6}$ at follow up in patients with restrictive physiology who also had restriction at follow up, compared with those in whom restriction resolved. This finding is in agreement with the results reported by Gatzoulis et $a l .^{3}$

We are aware of the limitation of E deceleration time as a marker for restriction, particularly in infants and children with high heart rates. It is also influenced by age, loading condition, and atrial pressures, and therefore this variable cannot be used as the only test for restriction. ${ }^{6}$ In our study, however, neither age nor heart rate was different in the two groups. At follow up heart rate was less than 100 beats/ min, and when corrected for heart rate, patients with restrictive physiology had a significantly shorter $\mathrm{E}$ deceleration time $(p<0.01)$. Early heart rates were too high and E deceleration time could not be obtained in most patients. E deceleration time is of no value for characterisation of these patients early after repair.

QRS DURATION

There were no differences in QRS duration between patients with and without restriction. This contrasts with the previous work of Gatzoulis et al who reported shorter QRS duration and fewer ventricular arrhythmias in patients with restrictive physiology. ${ }^{4}$ Follow up in their study was more than 20 years, however, and QRS prolongation progresses with time. ${ }^{7}$ The lack of difference in QRS duration between patients with and without restriction also seems to be in disagreement with our recent work. ${ }^{5}$ In that study, QRS duration was prolonged in patients without restriction with transannular patch repair and there was no overall group difference in QRS duration. The QRS data in our study are not surprising given the short follow up and small number of patients without restriction with transannular patch repair.

While restrictive RV physiology early after repair and at mid-term follow up seem to be related, it is not clear whether the substrate for this physiology is the same as previously reported late after surgery performed up to three decades ago. ${ }^{34}$ In the study by Gatzoulis et $a l,{ }^{4}$ only one patient had a transannular patch repair, and other preoperative and operative factors such as fibrosis may be more important for the evolution of restriction in these patients from an early surgical era. Longitudinal studies on our patients are required to address this question. 
LIMITATIONS

We were not able to obtain complete follow up data on all patients. All eligible patients were invited to participate, however, and apart from overseas patients, no selection was made. Some data have been reported as part of two earlier studies by our group..$^{2-5}$ In these previous studies, we focused on other aspects of diastolic physiology. The main purpose of the present study was to assess evolution of diastolic RV physiology, and it was therefore of vital importance to record and evaluate the presence of restrictive physiology in a uniform way. We are confident that the assessment of diastolic physiology is correct and the data obtained valid.

CONCLUSIONS

The strongest predictor for early RV restrictive physiology was the need for transannular patch repair. Restrictive physiology resolves in some patients at follow up, however, restriction persists in many patients. In fact, the strongest predictor for restrictive RV physiology at midterm follow up was the presence of early restriction. Furthermore, patients without early restriction are highly unlikely to have restriction later. The clinical importance of this new information is obvious. In most patients, assessment of RV diastolic physiology can predict subsequent diastolic physiology. Thus, patients without restriction with transannular patch repair should be followed carefully for long term adverse effects of pulmonary regurgitation, whereas patients with restriction, regardless of the type of outflow tract repair, may be protected from the potentially deleterious effects of pulmonary regurgitation.

Dr Norgård was supported by grants from Unger Vetlesen Medical Fund and the Norwegian Research Council.

1 Redington AN, Penny D, Rigby ML, et al. Antegrade diastolic pulmonary artery flow as a marker of right ventricular restriction after complete repair of pulmonary nary valve stenosis. Cardiology in the Young 1992;2:382-6.

2 Cullen S, Shore D, Redington AN. Characterisation of right ventricular diastolic performance after complete repair of tetralogy of Fallot. Restrictive physiology predicts slow postoperative recovery. Circulation 1995;91:1782-9.

3 Gatzoulis MA, Clark AL, Cullen S, et al. Right ventricular diastolic function 15 to 35 years after repair of tetralogy of Fallot. Restrictive physiology predicts superior exercise performance Circulation 1995;91:1775-81.

4 Gatzoulis MA, Till JA, Somerville J, et al. Mechanoelectrical interaction in tetralogy of Fallot. QRS prolongation relates to right ventricular size and predicts malignant ventricular to right ventricular size and predicts malignant ventricular

5 Norgård G, Gatzoulis MA, Moraes F, et al. The relationship between type of repair and right ventricular diastolic physibetween type of repair and right ventricular diastolic physi-
ology in postoperative tetralogy of Fallot: implications for ology in postoperative tetralogy of Fallot: implica

6 Johannessen KA, Cerqueira M, Veith RV, et al. Influence of 6 Johannessen KA, Cerqueira M, Veith RV, et al. Influence of sympathetic stimulation and parasympathetic withdrawal
on Doppler echocardiographic left ventricular diastolic filling velocities in young normal subjects. Am f Cardiol 1991; 67:520-7

7 Gatzoulis MA, Till JA, Redington AN. DepolarizationFallot. The substrate for malignant ventricular arrhythmias? Circulation 1997;95:401-4. 